\title{
PRÁCTICAS DE DURACIÓN DE LA PEQUEÑA MINERÍA CHILENA DESDE UN ENFOQUE ETNOGRÁFICO' ${ }^{1}$
}

\author{
PRACTICES OF DURATION OF SMALL CHILEAN \\ MINING FROM AN ETHNOGRAPHIC APPROACH
}

\section{Pamela Francisca Jorquera Álvarez ${ }^{2}$}

\section{RESUMEN}

El artículo discute y muestra como en una pequeña ciudad del norte Chile - Inca de Oro - se producen prácticas que expresan y celebran la actividad minera pirquinera, permitiendo la duración de la misma en el contexto local. Dichas prácticas tensionan el contexto nacional donde se privilegia una forma de explotación - la gran minería- en detrimento de otras formas como la Pirquinería. Para lo anterior se muestran las prácticas observadas y problematizadas gracias al trabajo etnográfico llevado a cabo por la autora. Este documento se divide en cuatro secciones, la primera contiene el abordaje teórico-conceptual del artículo, la segunda se refiere a los aspectos metodológicos, la tercera presenta una breve descripción de la actividad Pirquinera desarrollada en la localidad, y posteriormente narra la fiesta cívica chilena del Combate Naval de Iquique observada en la pequeña ciudad de Inca de Oro. Finalmente, en la cuarta, se reflexiona sobre los vínculos entre ambas narraciones mostrando como la celebración del Combate Naval de Iquique permite la expresión de aspectos propios de la localidad orientados al reconocimiento y duración de la actividad Pirquinera y sus pirquineros.

Palabras claves: Minería; local; identidad; Chile.

\section{ABSTRACT}

This paper discusses how a small town in northern Chile, Inca de Oro, expresses and celebrates practices that allow the artisan mining to persist in the future. However, these practices clash with the broader national context in which industrial mining is promoted against the small-scale artisan mining. Thus, this paper describes and analyze these practices, based on ethnographic fieldwork conducted by the author. This paper is divided in four sections: the first one describes the theoretical-conceptual approach, the second refers to the methodological aspects, the third presents a brief description of mining activity carried out in site, and later narrates the Chilean civic festivity "the Iquique naval combat" as performed in Inca de Oro; and finally, the fourth part is an analysis that shows how the celebration of the Iquique naval combat allows the expression of local meanings related to the recognition and persistence of the small-scale artisan mining and its actors.

Keywords: mining; local; identity; Chile.

\footnotetext{
${ }^{1}$ Pesquisa realizada com fomento da CAPES.

${ }^{2}$ Professora Departamento de Antropologia, Universidad de Chile. E-mail: pjorquera@facso.cl
} 


\section{INTRODUCCIÓN}

Chile es conocido a nivel mundial por la actividad minera que desarrolla a lo largo de su territorio. Económicamente hablando la minería corresponde a casi la mitad de las actividades producidas en el territorio. En la tabla 1 se observa los principales minerales explotados, siendo el más importante el cobre.

Tabla 1: Producción y reservas en Chile 2019.

\begin{tabular}{ccccc}
\hline Mineral & Producción en Chile & $\begin{array}{c}\text { Participación en la } \\
\text { producción mundial }\end{array}$ & $\begin{array}{c}\text { Ranking en la } \\
\text { producción mundial }\end{array}$ & $\begin{array}{c}\text { Participación en } \\
\text { reservas mundiales }\end{array}$ \\
\hline Cobre & 5,79 millones de TM & $29 \%$ & 1 & $23 \%$ \\
Oro & $37,85 \mathrm{TM}$ & $1,1 \%$ & 14 & $7 \%$ \\
Plata & $1.190 \mathrm{TM}$ & $4,4 \%$ & 7 & $4,6 \%$ \\
\hline Molibdeno & 54,76 mil TM & $18,9 \%$ & 2 & $7,8 \%$ \\
\hline Hierro & 14 millones de TM & $<1 \%$ & 15 & $<1 \%$ \\
\hline
\end{tabular}

TM: toneladas métricas. En todos los casos, excepto el hierro, se muestra el contenido de mineral fino Fuente: Cifras actualizadas de la minería, Consejo Minero 2020: 4

Chile es considerado un país de éxito minero, sobre todo en lo que refiere a las explotaciones realizadas en la parte norte de su territorio, lugar donde existen grandes cantidades de minerales que han atraido a diferentes sociedades desde tiempos precolombinos (Salazar 2003-2004, Romero 2011). Este éxito minero se expresa en el desarrollo de la Gran Minería, rubro donde se centran las acciones del Estado. La centralidad en la Gran Minería ha invisibilizado otras formas de explotaciones mineras consideradas medianas, pequeñas o artesanales. Dentro de las que se cuenta la llamada Pirquinería, interés de este artículo.

La Pirquinería es definida por el Ministerio de Minería en su Reglamento de seguridad Minera de la siguiente forma: "Explotación artesanal de las zonas más enriquecidas, sin programación de las secuencias operativas, buscando maximizar la utilidad y minimizar el capital invertido a expensas de la vida útil del yacimiento minero y/o de la seguridad de sus trabajadores". (Decreto Supremo132, título XIV: 2004, 152)

Esta definición evidencia una mirada que enfatiza posibles aspectos negativos, como la falta de planificación, el riesgo para la vida útil de las minas. Esa visión negativa sumada a las nuevas medidas de seguridad exigidas después del caso de los 33 mineros $^{3}$ son vistas por los pirquineros como barreras para la realización de la actividad, sumándose a los motivos para que cada vez menos personas puedan y quieran desarrollarla.

\footnotetext{
${ }^{3}$ El 5 de agosto de 2010, 33 mineros sufrieron un accidente que los dejó enterrados a 720 metros de profundidad, en la mina San José ubicada en la ciudad de Copiapó. Esa mina era explotada por la minera privada San Esteban Primera S.A. Durante 70 días los mineros estuvieron enterrados, 17 de ellos no se tuvo noticias sobre el estado de ellos o si habían alcanzado el refugio que se encontraba dentro de la mina para esos fines. El 22 de agosto fueron encontrados con vida, siendo el 13 de octubre el día en que pudo comenzar el rescate. El rescate duró 48 horas, horas que fueron transmitidas por televisión. Este accidente tuvo como consecuencia que la fiscalización en torno de las explotaciones mineras se endurecieran por parte del Ministerio de Minería.
} 
En este contexto modernizador, donde el Estado chileno privilegia y promueve la gran Minería, surge, en una pequeña localidad, prácticas que expresan, reconocen y celebran la actividad pirquinera permitiendo la duración y trascendencia de la misma. El presente documento reflexiona sobre las prácticas de duración en Inca de Oro, pequeña ciudad minera-pirquinera ubicada en el norte chileno.

\section{INCA DE ORO, UNA PEQUEÑA CIUDAD}

Inca de Oro se ubica en la tercera región de Chile, pertenece a la comuna de Diego de Almagro, de la provincia de Chañaral ubicada en pleno desierto de Atacama.

Administrativamente Inca de Oro es definida como una comunidad rural puesto que en ella habitan menos de 1.000 personas (CENSO; 2017). No obstante, el presente documento se centrará en las prácticas locales del pueblo más allá de la oposición rural-urbano. Para tal fin, la investigación se apoya en la concepción de situación dada definida por De La Pradelle (2007) que entiende como una secuencia de espacio-tiempo que conformará lo local como campo de observación. A través del análisis de una situación dada será posible elucidar las lógicas implícitas de los actores en un contexto social e históricamente creado. Así en Inca de Oro se sucederán diferentes situaciones que irán conformando lo local. En esas situaciones locales se construirán de forma continua universos prácticos y simbólicos propios de dicho pueblo.

Figura 1 - Provincia de Chañaral.

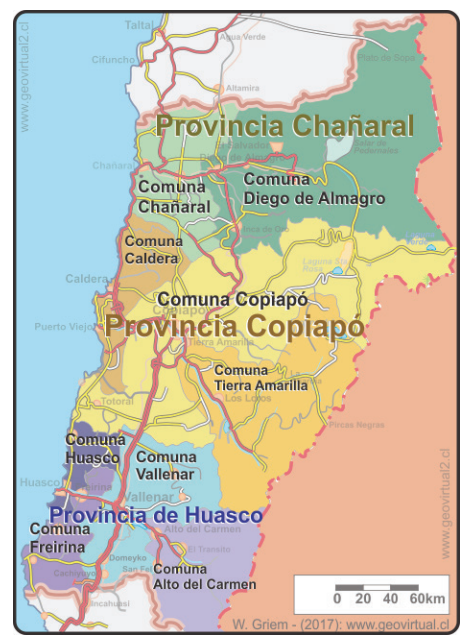

Fuente: www.geovirtual2.cl

Como forma de complementar lo anterior se utilizará el enfoque de pequeñas ciudades o petite ville definido por Michel Bozon (1984). Enfoque que subraya la importancia de los modos de vida, de las prácticas sociales y las relaciones sociales que se entretejen al interior de una pequeña ciudad. Dentro de una pequeña ciudad, los grupos sociales serán definidos por el contacto cotidiano, la coexistencia de los grupos como de los individuos y también por los conflictos que se sucedan. En ese 
sentido, formar parte de una pequeña ciudad significará estar dentro de una red de interconocimiento, en donde los individuos compartirán un conocimiento y códigos comunes. Esos códigos estarán dados por los valores compartidos, y por medio de ellos los habitantes de una pequeña ciudad podrán reconocerse como parte de un mismo pueblo.

La pequeña ciudad de Inca de Oro se caracteriza por la minería como actividad económica principal, la pequeña minería conocida como pirquinería. Dentro de los estudios hechos en comunidades semejantes (VIEZZER, 1978; GASCHO, 1982; ECKERT, 1985; VIVALLOS, 2007; ROMERO, 2011; ECKERT, 2012) se establece que las comunidades mineras comparten algunas características, tales como: cultura íntimamente ligada a la historia de la comunidad, identidad surgida en torno al trabajo minero y del producto de extracción, además de las transformaciones a las que deben enfrentar con los cambios en el escenario nacional e internacional. Aspectos propios de esta cultura se entienden por las duras condiciones de trabajo, el peligro y el riesgo constante de accidentes, los problemas de salud crónica, los bajos salarios, el costo ambiental y social producto de la contaminación del aire que produce el trabajo extractivo. Muchas de esas características hacen que las prácticas locales de esas pequeñas ciudades sean vistas como parte de un mundo tradicional condenado a la extinción frente a los embates de la Modernidad. En ese sentido este artículo tiene como objetivo mostrar las prácticas locales sucedidas en la pequeña ciudad de Inca de Oro.

\section{PRÁCTICAS DE DURACIÓN}

En el contexto de lo mencionado, se reconocerá que dentro de una pequeña ciudad se sucederan diferentes situaciones dadas que expresaran universos simbólicos y prácticas relacionadas con los valores compartidos por los habitantes de un pueblo. En este sentido, algunas de las prácticas suscitadas en Inca de Oro se reconocen como de duración. El concepto de duración es tomado de la teoría de Bachelard, quien la entiende como "permanecer en el tiempo" (apud Eckert y Rocha 2011: 8). Por lo que, las prácticas de duración serán aquellas que promuevan y posibiliten la permanencia en el tiempo de los valores de actividad pirquinera de Inca de Oro. En ellas, tiempo y espacio se entrelazaran en la observación de las rutinas, de los ritmos, de las continuidades y discontinuidades destinadas a hacer durar la actividad pirquinera.

\section{MATERIAL Y MÉTODOS}

En relación a los aspectos metodológicos, la investigación respondió a una Etnografía de la duración problematizada por las antropólogas brasileñas Cornelia Eckert y Ana Luiza de Rocha (2011, 2012). Propuesta de investigación centrada en analizar los múltiples estilos de vida, visiones de mundo sucediéndose en la sociedad compleja actual y su duración. Como se mencionó, 
el concepto de duración es tomado por las autoras de la teoría de Bachelard. Así las prácticas analizadas permiten la permanencia en el tiempo y espacio de la Pirquinería.

Además, la Etnografía de la Duración se entiende también como una propuesta ética puesto que reconoce que el conocimiento se construye en conjunto con los interlocutores. Quienes aceptaron participar de la investigación motivados por la oportunidad de dar a conocer sus experiencias como pirquineros, la actividad Pirquinería y de permanecer en el tiempo.

Cabe mencionar que la Etnografía se desarrollo por cuatro años de los cuales ocho meses viví en Inca de Oro. Gracias a la etnografía llevada a cabo pude conocer y construir una relación de confianza con mis interlocutores - hombres adultos mayores - quienes me presentaron la Pirquinería del oro, actividad que habían desarrollado durante gran parte de su vida y de la cual se encontraban distanciados en mayor o menor puesto que se enfrentaban a la vejez.

De esta forma pude saber que la mayor parte de ellos compartían una vida difícil, ya que, desde la infancia, debieron relacionarse estrechamente con el mundo del trabajo dentro o fuera de un núcleo familiar. En ese contexto la actividad pirquinera fue la elección que los llevó a enfrentar riesgos y vicios que, muchas veces, les produjeron desorden y soledad, pero también les dio la oportunidad de experimentar la libertad. Son esas dificultades y costos los que hacen a la Pirquinería una actividad digna de reconocer y sus pirquineros dignos de ser celebrados. Durante la etnografía observé diferentes prácticas en esa línea, siendo una de ellas la conmemoración del Combate Naval de Iquique en el pueblo, correspondiendo a una fiesta cívica de la que forma parte la identidad pirquinera de Inca de Oro.

\section{RESULTADOS}

\section{CONOCIENDO LA PIRQUINERÍA DEL ORO}

De acuerdo a las diferentes conversaciones sostenidas a lo largo de la Etnografía con mis interlocutores, supe que el trabajo pirquinero comienza con la identificación de la veta en la roca. Dicha identificación se produce solo gracias al ojo atento del pirquinero y de su conocimiento del territorio.

Así, pacientemente, busca alguna señal que le indique si por debajo de la tierra o, tal vez, dentro del cerro se encuentra un yacimiento. En esa tarea, el pirquinero puede decidir si explotará un pique o un túnel en el cerro. En ambos casos debe abrirse el camino en la roca o en la piedra, lo cual hace por medio de la colocación de explosivos en pequeños orificios que va distribuyendo de forma uniforme. Esos orificios los hace manualmente barrenando.

Para eso, el pirquinero se ayuda de una herramienta llamada barreno, la que va golpeando con un martillo creando los pequeños orificios mencionados. En ellos pondrá los explosivos que le permitirán abrir la roca y formar, poco a poco, las galerías que constituirán la mina. 
Después de cada una de las explosiones las galerías deben ser desocupadas, el pirquinero recoge los pedazos de roca en una carretilla, en el caso que su mina sea construida en un túnel, o en una mochila o capacho en la espalda cuando la mina es un pique.

De tratarse del último caso, el pirquinero deberá subir y bajar las veces que sean necesarias hasta lograr despejar las galerías. Cuando el pique alcanza una profundidad mayor, las piedras son sacadas con ayuda del torno ${ }^{4}$, de la pata de cabra y del huinche. Antiguamente era común hacer eso manualmente, usando las herramientas mencionadas, pero en la actualidad los pirquineros usan motores que cumplen la función del huinche, acelerando considerablemente el trabajo.

Lentamente el pirquinero va abriéndose camino en la tierra, identificando las vetas que contienen los minerales. Saber si en ellas hay oro, plata o cobre es producto de los años de trabajo, de la propia experiencia. Por eso mis interlocutores destacaron que cualquier aficionado no es pirquinero. Para lo cual mencionaron historias de esfuerzos frustrados de quienes, tras sacar muchas rocas de los cerros y de semanas de trabajo, no lograron encontrar ningún mineral que pudiera ser procesado y vendido.

De hecho, no basta con identificar el oro en la roca, también el pirquinero debe ser capaz de evaluar la cantidad que puede haber en ella, para saber si vale la pena el esfuerzo de la explotación. Para eso existe un proceso que permite medir la cantidad de mineral que se obtendrá, a lo cual llamaron de puruñar o cachear ${ }^{5}$

Para puruñar, el pirquinero coloca en un cacho de toro o buey, que ha sido partido por la mitad con anterioridad, un poco del material extraído de la roca, el cual debe primero moler y después agregarle un poco de agua, eso con el fin de que la roca se disuelva. Por medio de movimientos suaves va haciendo aparecer el oro, el cual se ve como pequeños puntitos de oro. De acuerdo al brillo de esos puntitos el pirquinero sabe si va por buen camino y si logra llenar una tapa de botella (cerveza o bebida) con ese oro puede decidir si continuará explotando el yacimiento o si es preferible buscar otro.

En la figura 2 se muestra el cacho de buey junto con la tapa de cerveza o bebida que constituyen las herramientas para puruñar, y en la figura 3 se muestra la acción de puruñar con el cacho de buey dejando a la vista el oro.

\footnotetext{
${ }^{4}$ Torno: máquina utilizada en los piques para subir el balde repleto de materiales solo con la fuerza humana del pirquinero. (Romero 2011:140).

${ }^{5}$ Los dos nombres son utilizados por los pirquineros para referirse a la herramienta: puruña o cacho. ocha 2011: p.la localidadiudadlan de banderas nacionales. erirse a la herramienta puruña o cacho de Inca de Oro, sino que tam
} 
Figura 2 - Herramientas para puruñar, cacho y tapa de botella de cerveza.

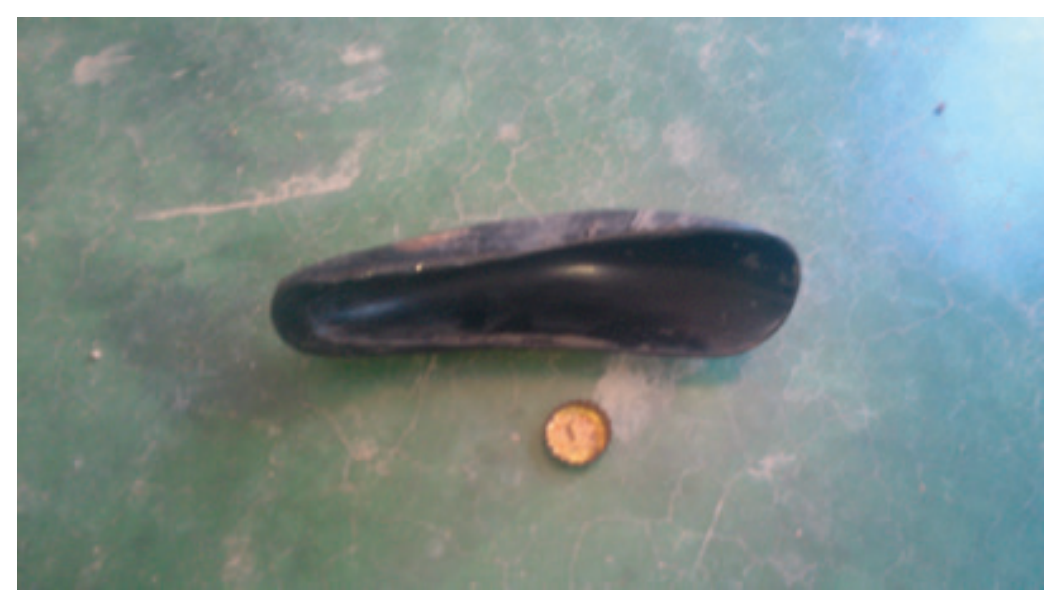

Fuente: De la autora, 2014

Figura 3 - Puruñando, oro.

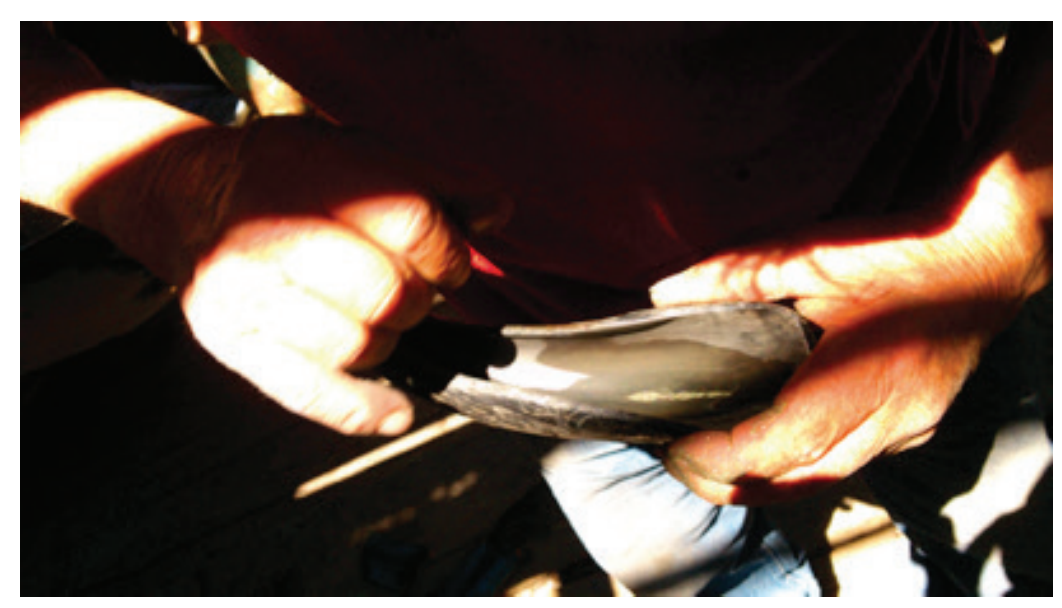

Fuente: De la autora, 2014

Durante la explotación de los yacimientos, el pirquinero se expone a riesgos importantes de sufrir accidentes, o incluso de encontrar la muerte. Muchas veces las explosiones hechas para abrir las galerías pueden alcanzarlos y dejarlos enterrados o, mientras trabajan en la mina, pueden caer cuando suben o bajan por las diferentes escaleras. Las siguientes citas expresan de primera fuente lo anterior.

Yo como minero he pasado unos peligros tremendos, he quedado cegado en los piques, he quedado enterrado tres, cuatro horas solo, y me han pasado cosas muy graves en las minas, $\mathrm{y}$ gracias a Dios que no he tenido accidentes grandes, por eso que para mi Dios es muy grande.... (Interlocutor adulto mayor 2).

Dada la posibilidad de sufrir algún tipo de accidente dentro de la mina, es central el conocimiento de la pirquinería. Es por eso que antes de entrar a las minas cada pirquinero tiene que estudiar bien el terreno y las características de la mina, ubicando posibles lugares en los cuales protegerse en 
el caso de suceder algún accidente, como un temblor o una explosión, entre muchos otros. En alguna situación así, puede ser más peligroso salir de la mina, por lo que es más cauteloso quedarse dentro en un lugar ya identificado.

Mis interlocutores me contaron que el conocimiento pirquinero era transmitido por los abuelos y los padres, siendo una de las primeras lecciones saber cuidar la vida. Así, aún cuando el desorden, los vicios y el alcohol está muy presente en la vida del pirquinero, a la hora de trabajar una mina se hace con mucho cuidado.

\begin{abstract}
No, no, gracias a Dios nunca, nunca me ha pasado ninguna cosa en las minas, he tenido siempre esa precaución de cuidar mi pellejo, porque el pellejo de uno vale mucha plata y cualquier cosa que a uno le falte, cualquier cosa que a uno le quede mala, ya no es lo mismo, ya el cuerpo ya perdió una parte, un porcentaje de su fuerza, entonces uno tiene que cuidarse... (Interlocutor adulto mayor 3).
\end{abstract}

Además del riesgo de encontrar la muerte o de quedar con alguna deficiencia física, la Pirquinería también es riesgosa debido a la incertidumbre que conlleva. Incertidumbre de no saber si el esfuerzo hecho tendrá recompensa. Muchas veces los pirquineros trabajan en minas de las que no logran sacar el oro suficiente para pagar la inversión y tener ganancias. Por lo que en ella también hay mucho de azar y de suerte nunca se sabe si se obtendrá lo esperado.

Pese a esas incertidumbres y los riesgos a los cuales se exponen, el desgaste, la meticulosidad y la lentitud del trabajo, la Pirquinería los sedujo por la libertad que les ofreció, la falta de jerarquías, la oportunidad de tomar las propias decisiones, de trabajar de forma autónoma, sin jefes ni horarios. Por eso, pese a todo, los pirquineros consideran su trabajo y vida bonita.

Pirquinero, es que es el mejor trabajo, ahí nadie le va a pedir documentos a uno, a menos que no sea para comprar explosivos, siempre en la minería. Tengo una mina que tiene 86 metros, yo la empecé a trabajar (...) ahí la tengo armada, el día menos pensado me canso y allá me voy a la mina y tengo que seguir haciéndole metros pa' abajo (Interlocutor adulto mayor 1)

La vida del pirquinero es bonita, la gente dice que es triste, que es sacrificada, pero es culpa de uno mismo. Porque si la mina es buena, más toma y más payasea...es, es raro el minero que haya aprovechado lo que ganan, todo se lo toman...yo soy uno de ellos (Interlocutor adulto mayor 2).

El trabajo minucioso, las precauciones que toman los pirquineros, contradicen la visión del trabajo pirquinero como desorganizado, mencionado en la Introducción de este documento, siendo la meticulosidad y el cuidado una de sus principales características. Así la visión del pirquinero como un minero desordenado en las secuencias operativas de la explotación, donde privilegiaría la utilidad en desmedro de la seguridad corresponde a una visión equivocada de la tradición pirquinera. 
El Combate Naval de Iquique, sucedió durante la Guerra del Pacífico o del Salitre o Guano (1879-1884), entre Chile y la alianza entre Perú y Bolivia. Este combate es especialmente recordado en Chile puesto que en él el Capitán Arturo Prat Chacón, a cargo de la corbeta chilena Esmeralda, motivó a sus soldados a luchar en contra del barco peruano Huáscar, aun cuando la diferencia de tamaño y de poderío bélico era diametralmente opuesta. En dicho combate, Arturo Prat Chacón perdió la vida defendiendo la corbeta chilena. Acto que fue considerado como un sacrificio valiente por la patria, sacudiendo la sociedad de la época, motivando a muchos chilenos a enlistarse para la guerra animados por el patriotismo demostrado por Prat.

El impacto que tuvo la epopeya pasó a constituir el norte de nuestras fuerzas combatientes, después de ella ningún chileno podía arriar el pabellón, ni rendirse, ni entregar nada al enemigo...ni buque, ni arma, ni bandera, ni ciudad, ni posición (Bravo 2014: 26).

Consecuentemente la fecha es recordada y conmemorada a lo largo de Chile, rindiendo honores por medio de desfiles cívicos y militares desde los propios miembros de la Armada chilena hasta los estudiantes en sus escuelas (Arévalo 2010). Mediante esos honores en Chile se exalta lo sucedido el 21 de mayo de 1879, utilizando el pasado y sacralizando la memoria de Prat con la intención de utilizar su figura y acto con fines propagandísticos. Eso porque las tragedias históricas tienen mayor influencia simbólica que los actos gloriosos, puesto que imponen deberes, obligaciones y exigencias tanto a las generaciones actuales como a las futuras (Defez apud Arévalo 2010).

Inca de Oro no se queda fuera de esta conmemoración, recordando el combate todos los años. La Escuela del pueblo, Emperatriz Sepúlveda Landeros, organiza un desfile, en el que los alumnos que forman la banda de la escuela abren el desfile. En él también participan otras organizaciones del pueblo como el Jardín Infantil Pincho, el Cuerpo de Bomberos y la Asociación Minera.

Tuve la oportunidad de presenciar el desfile el 2016, durante la realización de la Etnografía. Gracias a eso me familiaricé con los preparativos de la fiesta, como los ensayos de la banda escolar a la que veía deambular por las calles del pueblo cuando me encontraba conversando con mis interlocutores o sentadas en los bancos de la plaza. Así evidencié la importancia del evento dentro del pueblo, puesto que de alguna forma todos se involucran en él, sea porque un sobrino, nieto o amigo de la familia hace parte de la banda, o porque ayudan a los padres de los hijos a preparar las vestimentas especiales que usarán en ese día, en los bailes o en la representación del Combate, como la confección de la chaqueta de marinero del niño que personificó a Arturo Prat Chacón.

De esa forma, los incanos vibran con el desfile, haciendo vibrar la memoria colectiva de la comunidad (Halbwachs 2011), transmitiendo los valores tradicionales no solo de la nación chilena, sino que también del pueblo. Ese evento permite que los recuerdos afloren en las conversaciones 
cotidianas, destacando que, pese a la falta de recursos, antiguamente, las casas eran pintadas para la ocasión, siendo una forma de embellecerlas como la ocasión requería. Aun cuando esa práctica se ha perdido con los años, igualmente las casas son especialmente adornadas para la ocasión, limpiándolas con ahínco. El compromiso manifestado por la comunidad es una característica que enorgullece a los incanos, destacando que el evento se realiza el mismo 21 de mayo aun cuando sea fin de semana y en las calles del pueblo y no a puertas cerradas, como sucede en otras partes del país, donde las festividades ocurren en el interior de las escuelas o instituciones.

E1 21 de mayo de 2016, observé el desfile que comenzó con la aparición de la banda escolar y de representantes del Cuerpo de Bomberos, quienes se apostaron en la calle en frente del escenario debajo del fuerte sol de Inca de Oro. El acto comenzó con las palabras y discursos de bienvenida de las autoridades y con la narración del Combate Naval por parte de un profesor de la escuela. Después de la narración del Combate Naval, los estudiantes de la Escuela, lo representaron teatralizándolo. Posteriormente, diferentes grupos de estudiantes danzaron el baile nacional, la cueca y otros bailes de salón. Posteriormente comenzó el desfile en si. Primero desfiló el Jardín Infantil Pinocho, cuyos pequeños estudiantes fueron acompañados por sus madres, y después la Asociación Minera.

El desfile de la Asociación Minera fue encabezada por su presidente, que usó un casco y un chaleco de seguridad amarillos, diferenciándose del resto de los mineros, quienes lo hicieron con casos rojos, verdes o plomos y con chalecos rojos. El adulto mayor minero que desfiló detrás de él, lo hizo cargando el estandarte de la Institución y más atrás, en dos filas, el resto de los mineros socios de la Asociación. En la figura 4 se aprecia el desfile de la Asociación Minera.

Figura 4 - Desfile Asociación Minera de Inca de Oro.

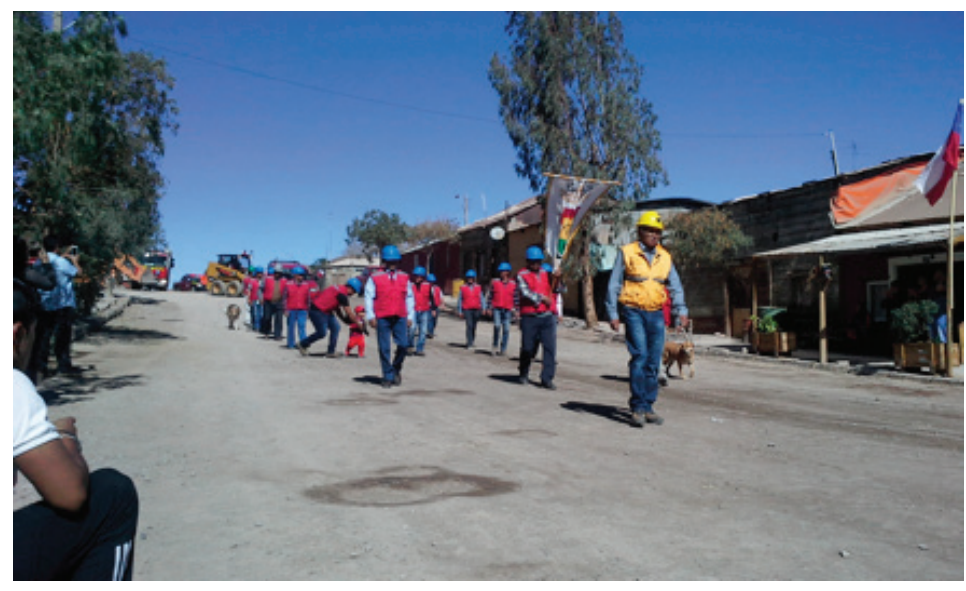

Fuente: De la autora, 2014.

Identifiqué a uno de mis interlocutores, quien caminaba lentamente debido a su pierna coja, situación que hizo que el desfile se ralentizara y se formara un espacio considerable entre él y el resto de los mineros. Como se aprecia en la Figura 5. A continuación de ellos desfilaron las maquinas de la Asociación, como las camionetas y las excavadoras. 
Figura 5 - Interlocutor (centro, casco plomo) desfilando.

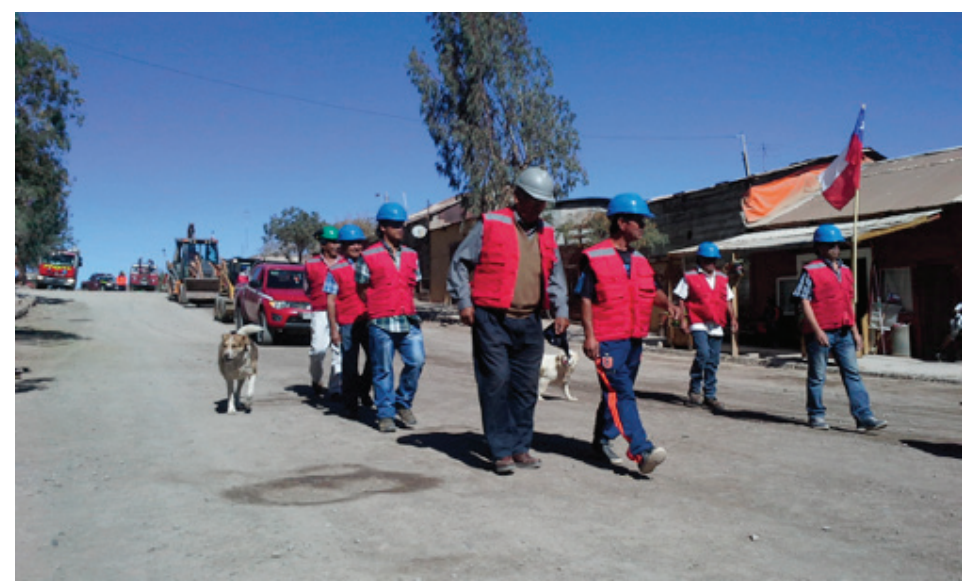

Fuente: De la autora, 2014.

Finalmente, cerraron el desfile los Bomberos con sus camiones y sonando las sirenas, lo que produjo mucho ruido sumado a los aplausos de los asistentes. Mientras escuchaba los comentarios de algunos asistentes que destacaban la diferencia con los desfiles anteriores que eran mucho más grandes y con más espectadores.

Terminado el desfile, las autoridades agradecieron y se despidieron de los participantes.

\section{DISCUSIÓN Y CONSIDERACIONES FINALES}

En el contexto chileno, se privilegia la forma de explotación conocida como gran Minería, donde hay mayor apoyo del Estado. Esto, sumado a las medidas de fiscalización por parte del mismo destinadas a regular la explotación de las faenas mineras, deja a la Pirquinería en una situación difícil, puesto que sumando a la visión negativa que se hace de ella, se le exige los mismos estándares que a la Gran Minería.

De acuerdo a lo anterior, y desde la visión de las personas mayores pirquineras, se asiste a un proceso de extinción de la Pirquinería, puesto que bajo esas condiciones nadie se interesa por desarrollarla. No obstante, en Inca de Oro se expresan prácticas de duración que tensionan la concepción hegemónica de la explotación minera.

Las prácticas de duración, orientadas a la permanencia en el espacio de la actividad pirquinera, expresan y celebran la actividad en esta pequeña ciudad del norte de Chile. Esta actividad, que puede ser considerada traspasada o superada se muestra como una situación dada posible dentro de un mundo considerado tradicional en camino a la extinción. En ese sentido José de Souza Martins (2008, p. 18) señala que la modernidad incorpora el mundo tradicional que nada tiene de moderno, incorporando sus relaciones sociales, sus relaciones de género y sus relaciones intergeneracionales, contrario a la visión de la modernidad como sinónimo de progreso y antónimo de lo tradicional. 
Es así como, durante la celebración del 21 de mayo, los habitantes del pueblo devuelven el lugar central de la actividad pirquinera en el escenario nacional permitiendo su duración.

Cabe destacar que la conmemoración del 21 de mayo el Estado-nación chileno, crea y narra una historia que la constituye. En este sentido, Anderson (2008) señala que la nación corresponde a una construcción social relacionada a aspectos simbólicos y a estrategias para su formación, por ejemplo, el uso de la lengua, de la palabra escrita, las celebraciones entre otros. En esa construcción el sentimiento de pertenencia cumple un papel importante. Anderson define nación como una comunidad imaginada, pues sus fronteras son imaginadas, dado que un miembro de una nación no podrá conocer a los otros miembros que la forman. Por ser una comunidad imaginada, el sentimiento cumple un papel relevante en la imaginación del otro que comparte algo común, el amor a la nación de la que forma parte. El amor a la nación permite que las personas se sientan unidas unas a otras aun cuando nunca se conozcan. Es ese sentimiento que posibilita el sacrificio por la patria.

Para Gupta (2007), el sentimiento por la nación, por la patria será más apasionado todavía, mas irracional de lo que afirma Anderson. A partir de esa falta de racionalidad será posible entender porque hay personas dispuestas a dar la vida por la patria, como el caso del capitán Arturo Prat Chacón, o de cometer actos que considerados irracionales para otros.

En el contexto del nacionalismo y de la comunidad imaginada de Anderson, las celebraciones cívicas en los Estados-nación modernos cumplen un papel fundamental para producir unidad, sacralizando la imagen del Estado (Vianna y Parada 2002). Esta conmemoración toma ribetes propios en el norte de Chile, donde la construcción de la nación chilena se exacerba. No debemos olvidar que su telón de fondo está dado por la Guerra del Pacífico con Bolivia y Perú, situación que exige al Estado-nación una construcción de identidad que exalte al extremo la figura del héroe nacional, representado en el Capitán Arturo Prat Chacón. Esta construcción nacionalista forma parte de los contenidos curriculares educacionales, realizándose cada año un acto que permite revivir el acto heroico y transmitirlo a las nuevas generaciones (Mondaca et al. 2014).

Tal como lo muestra el relato de la conmemoración en Inca de Oro, el Estado-nación chileno se sirve de este tipo de prácticas para exaltar la identidad chilena y, en consecuencia, la diferenciación exacerbada con nuestros vecinos. Prácticas necesarias en un contexto territorial de migraciones fronterizas constantes y cotidianas como ocurre en el norte chileno (Mondaca et al. 2013). De la misma manera, los habitantes del pueblo se sirven de esas prácticas para honrar y destacar la actividad pirquinera que los caracteriza y los diferencia en la zona.

De la misma forma que el desfile del 21 de mayo dramatiza la nación chilena y expresa los valores nacionales a transmitir y reforzar, el desfile dramatiza la Pirquinería y expresa sus valores a transmitir y reforzar. Las personas que participan del desfile, performatizan (Butler 2013, Vianna y Parada 2002) el amor por la nación y la pirquinería. Al performatizar, este tipo de festividades cívica 
en Inca de Oro produce un involucramiento corporal, experimentado en la participación del desfile ya sea en la exhibición de los cuerpos, es decir desfilando, o como un mero espectador.

El desfile del 21 de mayo permite a los incanos sentirse parte de algo mayor, de la nación chilena, pero a su vez les otorga un espacio propicio para celebrar su identidad pirquinera, es decir, formar parte de un pueblo con una historia y valores compartidos. El desfile exalta, refuerza, dramatiza los valores mineros representados en sus pirquineros, hombres envejecidos que muestran en sus cuerpos las marcas de la actividad, como la persona mayor que mismo cojeando participa de la celebración.

Esta celebración cívica asimila los actos heroicos, tanto del capitán Arturo Prat Chacón como de los pirquineros envejecidos. Tanto Prat como los pirquineros son héroes que ofrecen sus vidas, sus cuerpos por el bien mayor que representa la nación chilena. Esto porque la Pirquinería sería la base donde se sustenta el éxito Minero del país. No es por casualidad que la pensión recibida por los pirquineros adultos mayores corresponde a una pensión especial otorgada por el Estado de Chile a las personas que realizaron actos especialmente meritorios en beneficio del país, más allá de su beneficio personal.

La celebración del 21 de mayo en Inca de Oro, exhibe los cuerpos de los pirquineros, cuerpos masculinos y viejos. Cuerpos que evidencian el valor del trabajo, el esfuerzo de la actividad. Mostrando la valentía, la virilidad y el orgullo que produce la actividad pirquinera en los habitantes del pueblo. El desfile refuerza y expresa la identidad del pueblo, la actividad pirquinera con sus valores. Valores que deben ser reconocidos y celebrados puesto que permiten entender porqué esta actividad debe permanecer el espacio, debe durar. Así el desfile del Combate Naval de Iquique en Inca de Oro corresponde a una práctica de duración de la Pirquinería y de sus pirquineros.

\section{AGRADECIMIENTOS}

Agradezco a la Coordenação de Aperfeiçoamento de Pessoal de Nível Superior (CAPES) de Brasil por otorgarme la beca con la cual fue posible llevar a cabo esta investigación. Especialmente agradezco a los interlocutores, personas mayores por compartir conmigo sus experiencias y recibirme en sus casas.

Finalmente, agradezco a Cornelia Eckert, Paulina Osorio, Gloria Zavala, Diego Salazar y Francisco Garrido.

\section{REFERENCIAS}

ANDERSON, B. Raízes culturais e As origens da consciência nacional. En: Comunidades imaginadas. Reflexões sobre a Origem e a Difusão do Nacionalismo, p. 35-83. Ediciones São Paulo, Companhia das Letras, 2008. 
ARÉVALO, A. Héroes, tradiciones y poder. El caso de Chile en la Guerra del Pacífico. Revista F@ RO-Estudios Año 6-Numero 12- II semestre, 2010.

BRAVO, G. Condell en el Combate Naval de Iquique. El boletín de la provincia de Marga-Marga Año III No 10, 2014.

BUTLER, J. Problemas de gênero. Feminismo e subversão da identidade. Civilização Brasileira, 2013.

CERTAU, M. Andares de la ciudad y Relatos de espacio. En La invención de lo cotidiano I. p. 103-142, ITESO, México, 2010.

CONSEJO MINERO. Cifras actualizadas de la minería. Disponible en: www.consejominero.cl

DEBERT, G. 1999. A reinvenção da velhice. Universidade de São Paulo: Fapesp, 2020.

ECKERT, C., Y ROCHA, A. Etnografia da duração nas cidades em suas consolidações temporais. Revista de Ciencias Sociales, (34):107-126, 2011.

ECKERT, C. Memória e Trabalho: Etnografia da duração de uma comunidade de mineiros de carvão (La Grand-Combe, França). Porto Alegre. Editora Appris, Brasil, 2012.

GUPTA, A. Imagining nations. En: NUGENT, David and VINCENT, Joan. A Companion to the Anthropology of Politics. Oxford, Blackwell, pp. 267-281, 2007.

HALBWACHS, M. Memoria colectiva y memoria histórica. Prensa de la Universidad de Zaragoza, España, 2011.

MARTINS, J. A sociabilidade do homem simples. Editora Contexto. 2015.

MATTA, R. Carnavais, malandros e heróis. En Carnavais, malandros e heróis para uma sociología do dilema brasileiro. p. 47- 82. Editora Rocco, 1997.

MONDACA, C., RIVERA, P. y GAJARDO, Y. Educación Parvularia e inclusión en el norte de Chile. Formando pequeños chilenos en las aulas de Tarapacá. Alpha (Osorno) (39): 251-266, 2014. 
MONDACA, C., RIVERA, P. y AGUIRRE, C. La escuela y la guerra del pacífico: Propuesta didáctica de historia para la inclusión educativa en contextos transfronterizos del norte de Chile. Si Somos Americanos, 13 (1): 123-148, 2013.

MINISTERIO DE ENERGÍA CHILE REGLAMENTO DE SEGURIDAD MINERA. Decreto Supremo No 132, 2004. Disponible en: www.mineria.gob.cl.

ROMERO, I. Pirquineros del Oro de la Sierra Jesús María: Una mirada etnográfica. Memoria para optar al título de Antropólogo Social. Universidad de Chile, 2011.

SALAZAR, D. Arqueología de la Minería: Propuesta de un Marco Teórico. Revista de Antropología n. 17. Facultad de Ciencias Sociales, Universidad de Chile, 2003-2004.

VIANNA, A. y PARADA, M. Infância e nação em desfile: o Desfile da Juventude e a Hora da Independência. En: Gestar e gerir. Estudos para uma antropologia da administração pública no Brasil. Rio de Janeiro, p. 85-110. Relume Dumará, 2002. 
